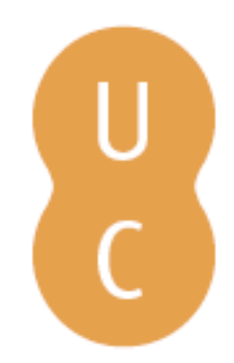

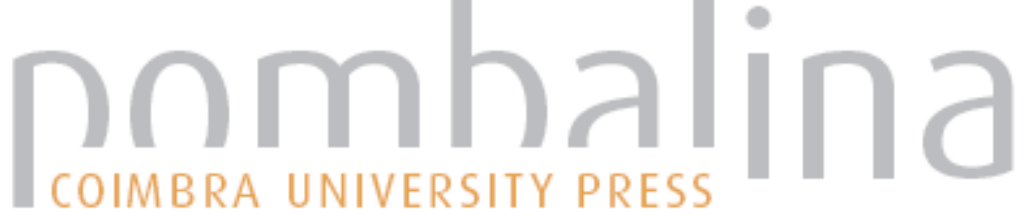

\section{Neurodesenvolvimento e comportamento}

Autor(es): $\quad$ Oliveira, Guiomar

Publicado por: Imprensa da Universidade de Coimbra

URL

persistente: URI:http://hdl.handle.net/10316.2/43113

DOI: $\quad$ DOI:https://doi.org/10.14195/978-989-26-1300-0_12

Accessed : $\quad$ 26-Apr-2023 10:54:56

A navegação consulta e descarregamento dos títulos inseridos nas Bibliotecas Digitais UC Digitalis, UC Pombalina e UC Impactum, pressupõem a aceitação plena e sem reservas dos Termos e Condições de Uso destas Bibliotecas Digitais, disponíveis em https://digitalis.uc.pt/pt-pt/termos.

Conforme exposto nos referidos Termos e Condições de Uso, o descarregamento de títulos de acesso restrito requer uma licença válida de autorização devendo o utilizador aceder ao(s) documento(s) a partir de um endereço de IP da instituição detentora da supramencionada licença.

Ao utilizador é apenas permitido o descarregamento para uso pessoal, pelo que o emprego do(s) título(s) descarregado(s) para outro fim, designadamente comercial, carece de autorização do respetivo autor ou editor da obra.

Na medida em que todas as obras da UC Digitalis se encontram protegidas pelo Código do Direito de Autor e Direitos Conexos e demais legislação aplicável, toda a cópia, parcial ou total, deste documento, nos casos em que é legalmente admitida, deverá conter ou fazer-se acompanhar por este aviso.

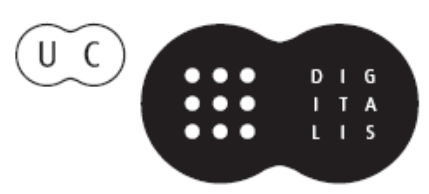


Capítulo 12.

Neurodesenvolvimento

e comportamento
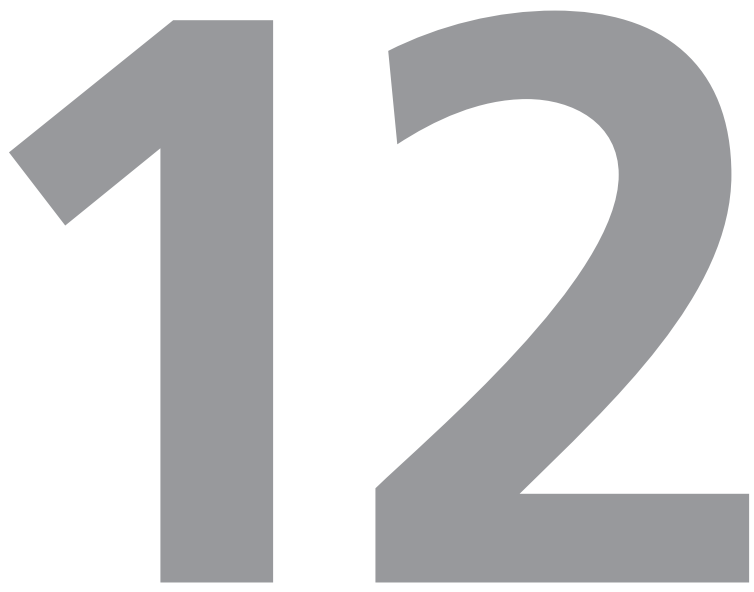

\section{Guiomar Oliveira}




\subsection{CONTEXTO}

Podes ensinar-me como se cresce, ou isso é indizível como a melodia ou a sedução? Emily Dickinson (1862).

O neurodesenvolvimento duma criança pode definir-se como um processo progressivo de aquisição de competências psicomotoras e comportamentais, cada vez mais complexas, que Ihe permita vir a adquirir autonomia pessoal, doméstica e social, com plena adaptação ao meio social e cultural em que vive.

Este tema, exclusivo da criança, só foi merecedor do interesse da comunidade científica na transição do século XIX para o XX, na época em que esta deixou de ser considerada como um adulto em ponto pequeno. Em simultâneo, as disfunções desta área começaram a ser classificadas em patologia, e em paralelo foram desencadeados planos específicos de intervenção à semelhança do que já se fazia com os outros problemas de saúde.

A compreensão da base, e dos fatores determinantes do desenvolvimento psicomotor (DPM) e comportamento infantil, bem como o seu modo de avaliação e intervenção tem sido objeto de múltiplas teorias.

Da vasta literatura, destaco alguns pontos que considero de grande utilidade para o conhecimento do tema e para a prática clínica.

Arnold Gesell, da Universidade de Yale, considerou o DPM e o comportamento como um processo contínuo e evolutivo que decorre da maturação física, incluindo a neuronal, que atravessa várias etapas, numa sequência ordenada, e previsível. Nos anos 20 do século passado, estabeleceu as suas "normas" ao avaliar, de um modo longitudinal, um grupo saudável de crianças. Ficaram desde então conhecidos os milestones ou marcos do DPM. Significa então, que as crianças em determinadas idades, consideradas chave para avaliação (veremos mais à frente quais são), atingem certas capacidades. Este conhecimento foi e é tão útil, que atualmente a maioria dos testes de avaliação se baseia nestes marcos desenvolvimentais, reveladores de maturação neuronal. Ronald Illingworth, discípulo de Gesell, introduziu esta experiência na Europa e fundou o primeiro Centro de Estudos em Neurodesenvolvimento na Universidade de Sheffield. Formou-se então a escola de pediatras comunitários ingleses dos anos sessenta. O livro de desenvolvimento infantil "From birth to five years: Children's developmental progress" publicado por Mary Dorothy Sheridan em 1973, disso é exemplo.

Alfred Binet e Terman Simon, criaram o conceito de quociente de inteligência (QI), posteriormente aplicável por outros autores ao desenvolvimento psicomotor - quociente de desenvolvimento (QD) nas idades pré, e escolar. Este valor quantitativo, resulta da razão entre o nível da idade mental (funcional) do indivíduo (obtida através de avaliação formal com provas padronizados das funções desenvolvimentais e cognitivas) e a sua idade cronológica. Na generalidade das provas, os valores normais destes quocientes variam entre a média de 100 (idade 
mental sobreponível à cronológica), e dois desvios padrão (DP-15); $100 \pm 30$.

Jean Piaget, estudou as bases biológicas do desenvolvimento infantil e postulou que a criança aprende através de uma interação ativa com o seu meio ambiente, antecipando as teorias atuais do active learning, e do construtivismo. Descreveu estádios neurodesenvolvimentais, sequenciais, clarificando o modo como a criança compreende e interfere no mundo em que habita.

Os autores Freudianos, e Neo Freudianos como Erik Erikson, deixam-nos como conhecimento irrefutável que o contexto sócio ambiental do indivíduo, particularmente na sua fase infantil, influencia marcadamente o seu comportamento e o futuro da Sociedade. Daí a tão famosa citação por Freud da frase de William Wordsworth (1770 - 1850) "The Child is father of the Man".

O Behaviorismo, e a teoria da aprendizagem social, consideram que a modelação comportamental é central na aprendizagem da criança. Valorizam a aprendizagem através do ensino passivo e repetitivo.

Vygotsky, salienta a teoria sociocultural e o conceito da criança e o seu contexto (cultura, história, meio social) como uma unidade. Destaca que o processo de ensino - aprendizagem deve ser adaptado à "zone of proximal development", ou seja, a criança por si própria aprende ao seu nível funcional; mas se o ambiente for estruturado motivante e facilitador aprenderá a um nível superior - o seu nível potencial. Este patamar só será atingido com um processo "scaffolding" em que o professor/mentor, passo a passo, vai conduzindo e modelando estratégias até o seu "aprendiz" alcançar o seu potencial máximo.

Maria Montessori, deu-nos conta de períodos sensíveis do desenvolvimento, como correspondendo a fases etárias da criança em que as aprendizagens de determinadas capacidades são naturais - janelas de oportunidade; como é o caso da aquisição da linguagem nos primeiros anos de vida.

O modelo ecológico, orienta-nos para uma análise do DPM e do comportamento da criança integrada no seu meio, uma vez que estes são determinados pela interação entre ambos: microssistema (pais, irmãos, cuidadores, professores); mesosistema (casa, infantário, escola); exosistema (serviço de saúde, social, educacional, segurança...); e macrosistema (valores culturais de justiça, proteção...).

Atualmente, as neurociências realçam o papel de todas as teorias, ao evidenciar que o cérebro e as suas funções sensoriais, motoras, emocionais, cognitivas superiores e mentais, indispensáveis ao comportamento adaptativo humano, têm uma base biológica de programação inata (Nature). No entanto, a sua expressão plena está dependente de modelos ou estímulos adequados da Sociedade - Ambiente (Nurture). Estes, têm que estar disponíveis em fases específicas de formação e maturação de circuitos neuronais, em que a sinaptogénese, biologicamente prevista, está dependente de estímulos específicos do meio ambiente. A sua ausência, apesar da capacidade de plasticidade cerebral, pode determinar a 
perda de oportunidade. Deve-se reter que o meio ambiente, o "ensino" ou modelos de aprendizagem, condicionam a arquitetura cerebral e a sua função, e que o binómio Nature/Nurture é bidirecional e indissociável.

Concluindo, a aprendizagem e a aquisição progressiva das diferentes capacidades psicomotoras e comportamentais depende de processos neuromaturacionais que decorrem de uma complexa e natural interação, bidirecional, entre fatores biológicos e ambientais. O equilíbrio dinâmico entre eles, pode ser ameaçado por múltiplas causas, ou por uma combinação entre elas, tornando a criança doente ou com essa vulnerabilidade.

\section{2 DESCRIÇÃO DO TEMA}

Apesar da maioria das crianças ser saudável, é conhecido que 15 a $20 \%$ sofre de alguma perturbação do neurodesenvolvimento, e mais vezes ainda, essa suspeita é referida; negá-la exige uma avaliação experiente. O diagnóstico e a intervenção precoces são relevantes no sentido em que os devidos esclarecimentos, conselhos, plano médico, e "ensino dirigido" devem ser atempados. Deste modo, os médicos que realizam consultas de primeira linha, em crianças, devem estar preparados para atestar a normalidade, ou o desvio do DPM e do comportamento como o estão para vigiar as displasias do desenvolvimento da anca, as cardiopatias congénitas, as alergias alimentares, e outras.

Assim, nas consultas de vigilância de saúde infantil e juvenil há dois contextos distintos na abordagem desta área: vigilância versus rastreio do DPM e do comportamento.

A monitorização ou vigilância, "developmental surveillance", carateriza-se por um processo contínuo e flexível de observações qualificadas, nas consultas de rotina, sem ter que recorrer a testes. Deve-se ouvir as preocupações dos pais acerca do desenvolvimento e comportamento da criança, colher a história clínica, observar cuidadosamente a criança neste contexto, identificar fatores de risco ou de proteção e proceder ao registo sucessivo dos dados. Poucos minutos serão necessários se tudo estiver bem.

Já rastreio, "screening", subentende a aplicação de um teste breve, desenhado para identificar problemas específicos desta área, em idades consideradas ideais (chave) para o efeito.

O reconhecimento precoce de atrasos ou desvios do neurodesenvolvimento requer contudo um conhecimento prévio, bem sedimentado, do modo como se avalia e interpreta a progressão das diferentes etapas, bem como do conceito da normalidade.

A idade de aquisição de determinadas competências psicomotoras e atitudes comportamentais, apesar de conhecida a sua progressão natural, apresenta uma enorme variabilidade. As fronteiras do normal nem sempre são claras de estabelecer, sobretudo no comportamento.

Determinar então, em contexto clínico, de consulta, se o neurodesenvolvimento (DPM e comportamento) de dada criança é ou não adequado para a sua idade cronológica é uma tarefa 


\section{AVALIAGAO DO DESENVOLVIMENTO \\ 4 AREAS - ACTIVIDADES ESPECIFICAMENTE HUMANAS}

(2)

POSTURA ERECTA E MARCHA
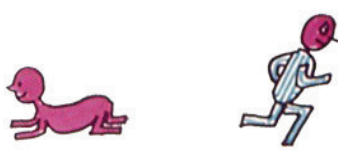

2) VISĀO MANIPULAGÁAO
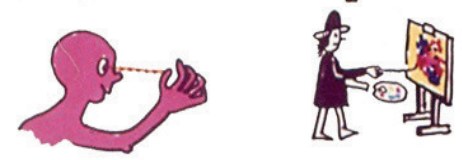

3) AUDIGȦO LINGUAGEM
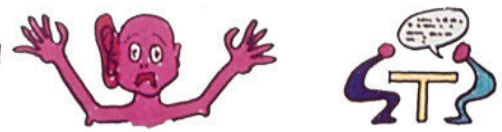

(4)

RELAGÖES SOCIAIS
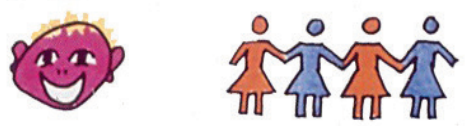

Figura 1. As quatro áreas de avaliação do neurodesenvolvimento correspondentes a atividades especificamente humanas (adaptado Henrique Carmona da Mota, Lições de Pediatria, 2002).

que exige conhecimento e prática. Para a facilitar propõe-se:

i) Avaliar o DPM e o comportamento decomposto em quatro áreas fundamentais, que correspondem a atividades especificamente humanas (figura 1):

1.Postura e motricidade global - postura ereta e marcha.

2.Visão e motricidade fína - visuomotricidade/coordenação óculo-manual/ visão-manipulação.

\section{Audição e linguagem.}

\section{Comportamento e adaptação social}

- atividades da vida diária/autonomia, relações sociais, emoção e comportamento.

ii) Realizar avaliações seriadas, na mesma criança, de modo a registar o perfil sequencial e evolutivo, a "velocidade de neurodesenvolvimento", das diferentes áreas e a sua uniformidade (figura 2).

Sabemos que, na criança normal, apesar das enormes variações interindividuais, o neurodesenvolvimento evolui de um modo sequencial e uniforme nas diferentes áreas que o compõem. Como exemplos: a criança segura a cabeça, senta-se e só depois se sustenta de pé; compreende várias palavras, mais tarde verbaliza-as e só então diz frases; o desenho da cruz antecede o do quadrado; comer com as mãos precede o uso da colher. A aquisição de diferentes capacidades de um modo não sequencial - desvios do desenvolvimento - é habitualmente sinal precoce de patologia. É o caso da criança que parece ter muita força nos membros inferiores, mas ainda não segura a cabeça (hipotonia axial com espasticidade dos membros inferiores); e outra que é capaz de verbalizar marcas de carros e os números 


\begin{tabular}{|c|c|c|c|c|c|c|}
\hline & 34 & $6^{n}$ & 74 & $12^{4}$ & $18^{n}$ & $24^{n}$ \\
\hline Locomocto & & & & & & \\
\hline manipulagro & & & & & & \\
\hline LINGUAGEH & & & & minimgen & & 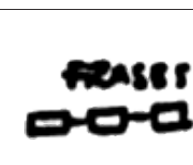 \\
\hline REL. SOcinis & & & & & & \\
\hline
\end{tabular}

Figura 2. Atividades características dos diversos escalões etários (ver detalhes no texto).

(adaptado Henrique Carmona da Mota, Lições de Pediatria, 2002).

das portas, mas não responde a ordens simples (como te chamas? Quantos anos tens?). A reter que a compreensão linguística (linguagem recetiva) deve ser superior à fala (linguagem expressiva).

A velocidade em adquirir conhecimentos e competências é relativamente uniforme nos diferentes domínios, embora cada criança possa ter áreas fortes e fracas (precoce na motricidade global, tardia na linguagem). No entanto, diferenças significativas entre áreas (superior a 15\%), com velocidades de aquisição não uniformes - dissociação entre áreas - sugerem a presença de patologia específica (atraso somente na área da linguagem - surdez ou distúrbio da comunicação e interação social; atraso só na área motora - paralisia cerebral, doença neuromuscular?).
Certamente que qualquer função em défice, a seu tempo interferirá negativamente na aquisição das capacidades globais. O DPM só para facilitação de análise se divide em áreas, na verdade estão interligadas.

Quando a velocidade de desenvolvimento global é uniforme, mas anormalmente lenta, afastando-se entre dois ou mais DP abaixo da média, pelo menos em duas áreas, consideramos estar perante uma situação clínica de atraso do desenvolvimento psicomotor global (ADPMG).

A progressão em todas as áreas é indispensável para que a criança atinja total autonomia pessoal (tomar conta dela), doméstica (ser autónoma em casa) e social (independência total). 
Todavia, nem todas têm o mesmo valor preditivo relativamente à capacidade futura de desempenho intelectual e social.

A postura e motricidade global, depende essencialmente da maturação e mielinização do sistema nervoso, de um sistema motor e sensorial funcionante e pouco do estímulo do meio ambiente. Tem pouca correlação com a inteligência futura, embora o atraso nas aquisições motoras possa ser um sinal precoce de disfunção neuronal global. Desde o primeiro escalão, representado pelo recém-nascido que, em decúbito ventral levantou pela primeira vez a cabeça, até à perfeita coordenação necessária para a corrida e o salto, cada período etário tem o seu desempenho motor pré-programado de acordo com a neuromaturação.

\section{A visão e motricidade fina - visuomo-} tricidade, tem por base a visão, a coordenação óculo-manual (motricidade fina) e a sua integração a nível cognitivo para resolver problemas, e desempenhar tarefas. Esta é uma das áreas que mais se correlaciona com a capacidade intelectual. $\mathrm{O}$ atraso persistente nas aquisições deste âmbito deve levantar a suspeita de défice intelectual, uma vez excluídos problemas de acuidade visual significativos, ou motores (mais raros). Neste domínio, nos primeiros meses de vida é sobretudo a interação visual que é avaliada. O bebé vê e observa o que o rodeia (fixa a luz e pessoas, sobretudo faces - olhos). No segundo semestre já é capaz de manipular objetos enquanto os observa; no final do primeiro ano resolve problemas (capaz de procurar um objeto escondido, ou arranjar modo de tirar um objeto dum frasco). Mais tarde na fase pré e escolar, as provas do grafismo (figuras geométricas), o desenho da figura humana, a construção com cubos, a reprodução de padrões no espaço e a resolução de problemas apresentam uma boa correlação com as capacidades cognitivas, sendo esta área a base das provas formais de avaliação da inteligência não-verbal (realização).

A audição e linguagem, é a função que mais se correlaciona com o nível intelectual futuro. Para que uma criança fale, tem que ouvir falar, saber e querer comunicar, compreender e interpretar os símbolos sonoros-fonemas e produzir palavras (processamento central), e ter uma infra-estrutura neuro muscular que Ihe permita falar (emitir palavras). A avaliação da linguagem usada no sentido lato de comunicação, não deve iniciar-se apenas com o aparecimento das primeiras palavras; antes existem os comportamentos pré- linguisticos (o alerta, o sorriso social, a atenção conjunta - olhar alternado entre o bebé e o adulto para o foco de interesse, o galreio com vocalização reciproca, o imitar, o apontar - protoimperativo para pedir e protodeclarativo para mostrar...) que são considerados atualmente, verdadeiros marcadores neuromaturacionais da cognição social humana. A demora no aparecimento destes marcadores da comunicação e interação social pode ser o primeiro sinal de uma perturbação do espetro do autismo. Atraso, em simultâneo, nas aquisições da linguagem e visuomotoras sugere uma perturbação do desenvolvimento intelectual ou défice intelectual.

O comportamento e adaptação social, e as aquisições das atividades da vida diária-autonomia, ao contrário das competências motoras, 
dependem largamente de fatores ambientais como seja a expectativa social, o treino e os modelos educacionais. Embora sendo necessários pré-requisitos cognitivos e motores para estas aquisições, são sobretudo fatores culturais que condicionam padrões comportamentais de autonomia alimentar e de higiene. A sua avaliação, deve ser interpretada no contexto global do desenvolvimento tendo sempre em conta o que é exigido à criança, no seu meio.

Antes de avançarmos para a avaliação dos marcos do DPM, em idades consideradas chave, vamos rever alguns conceitos estatísticos necessários na interpretação dos resultados. Avalia-se a criança e compara-se o seu desempenho com o de populações padrão estudadas para o efeito.

A idade média (mediana) de aquisição de determinada capacidade é aquela em que metade da população padrão, dessa idade, adquiriu essa competência. Por exemplo, a idade média em que se espera que uma criança ande sem apoio é aos 12 meses de idade cronológica, o que significa que até aos 12 meses, 50\% dos lactentes adquire a marcha.

As idades limite de aquisição de determinada competência situam-se ao nível de dois DP afastados da média. Ou seja, uma criança com desenvolvimento precoce adquirirá determinada competência antes da idade considerada média para o efeito. Se for depois, e ultrapassar a idade correspondente a dois DP da média, a suspeita de existir um problema deve ser colocada, e essa hipótese estudada. Tendo como exemplo a idade de aquisição da marcha sem apoio: 25\% fazem-no até aos 11 meses, 50\% até aos 12,75\% até aos
13, 90\% até aos 15 e 97.5\% até aos 18 meses (considerada a idade limite da normalidade; 2DP para além da idade média).

Uma nota importante, nas crianças que nasceram prematuras a idade a considerar na avaliação do DPM deve ser a idade corrigida, até fazerem dois anos. Um bebé com 9 meses de idade cronológica, que nasceu de 28 semanas de idade gestacional em vez das 40 [40 - 28 (tem menos 12 semanas - 3 meses)], o DPM esperado deve ser o de 6 meses.

Conhecer as idades médias de aquisição de competências consideradas "marcos do neurodesenvolvimento", e a sua variabilidade, é uma matéria indispensável para avaliar uma criança. De seguida abordaremos este conteúdo.

\section{Avaliação do neurodesenvolvimento \\ e interpretação dos resultados}

Em qualquer consulta deve ser feita a monitorização do DPM e do comportamento, já se abordou esse conceito previamente. O médico deve ter o cuidado de assinalar na página do desenvolvimento do Boletim de Saúde Infantil e Juvenil (BSIJ) a idade em que são adquiridas as competências assinaladas (e.g. sorri; anda sem apoio; aponta com o indicador...) tal como regista os percentis do crescimento e outros dados clínicos de relevo.

Este registo é de extrema relevância. Numa criança de idade pré-escolar (3 a 4 anos) que recorra à consulta por queixas de comportamento disruptivo (birras, agitação psicomotora) ou por atraso de linguagem, o conhecimento prévio da evolução do DPM é essencial. De facto, os pais raramente recordam com precisão as idades 
das aquisições básicas do DPM, e seria de extrema importância conhecê-las, uma vez que são verdadeiros marcos neuromaturacionais como é o caso da idade em que a criança andou, apontou e iniciou as primeiras palavras, de entre outras competências. Se se tratar de um caso de atraso de desenvolvimento Psicomotor Global (ADPMG), o que é provável, seria de esperar que estas competências tivessem surgido tardiamente. Desconhecendo esta informação a história torna-se mais difícil.

O rastreio do DPM deve ser feito em idades chave, ou sempre que houver queixas deste foro.

Uma nota prévia neste ponto. Quando os défices na aquisição das competências psicomotoras são graves, são os pais que se queixam ao médico, logo nos primeiros meses. Nos casos em que as dificuldades são discretas, estas podem passar despercebidas aos pais, e aos profissionais de saúde e da educação. Neste contexto é que os rastreios têm justificação de existir. Na verdade, se só recorrermos à monitorização, cerca de dois terços dos casos de anomalias ligeiras e mesmo moderadas não são detetadas.

Só mais tardiamente na idade escolar, as crianças serão referenciadas ao médico por dificuldades de aprendizagem escolar ou por problemas de comportamento desajustado como a perturbação de hiperatividade e défice de atenção e a recusa escolar. Salientar que a intervenção precoce e específica dirigida ao problema de cada criança não deve ser protelada.

Os problemas de neurodesenvolvimento graves (défice intelectual grave, autismo grave, paralisia cerebral, surdez profunda, cegueira e síndromes dismórficos) são evidentes nos primeiros anos de vida. Têm habitualmente uma repercussão marcada no desenvolvimento motor, sensorial e nas capacidades pré-linguísticas. $\mathrm{Na}$ idade pré-escolar (entre os dois e os cinco anos), manifestam-se as formas moderadas das patologias anteriores. Nesta fase, os défices têm sobretudo reflexo nas aquisições da linguagem, na capacidade gráfica (grafismo em atraso) e de resolver problemas, e no comportamento que se torna disruptivo (agitação psicomotora, irritabilidade, birras, desafio e oposição). A perturbação de espetro do autismo (diferentes níveis de gravidade), apresenta-se claramente nesta idade por uma combinação de défices na comunicação e nas relações sociais (entre pares e adultos - a criança não olha, não pede, não partilha), que se associa a comportamento rígido com tendência para interesses e atividades repetitivas e desviantes (abanar as mãos, rodopiar objetos, fixação no movimento repetido - máquina de lavar roupa, fascínio por botões de comandos, fios, números, letras, marcas...). As perturbações específicas do desenvolvimento da linguagem (muito comuns) também se diagnosticam nesta idade. Nestes casos só o potencial linguístico está afetado, todas as outras competências estarão intactas.

Teoricamente poderíamos considerar que numa população infantil bem seguida todas as patologias do neurodesenvolvimento congénitas (a grande maioria) deveriam ser conhecidas antes da entrada para o primeiro ciclo escolar. No período de idade escolar, somente as dificuldades específicas de aprendizagem escolar e défices muito discretos de funções cognitivas superiores (memória de trabalho, função executiva, atenção, 
motivação, comportamento social...) se revelariam.

A avaliação do neurodesenvolvimento deve ser integrada numa história clínica detalhada. Deve-se dar especial atenção a incidentes pré, peri e pós-natais, aos antecedentes pessoais no que diz respeito à progressão do DPM e "estilo" do comportamento. Os antecedentes familiares de patologias do neurodesenvolvimento devem ser minuciosamente pesquisados, assim como o ambiente social em que a criança habita. No exame objetivo para além do padrão de crescimento global, especialmente do perímetro craniano, não deixar de registar a presença de sinais dismórficos, anomalias de desenvolvimento noutros órgãos e da pigmentação cutânea (rastreio de síndromes neurocutâneos). O exame neurológico, do qual a avaliação do neurodesenvolvimento faz parte, deve atender particularmente à avaliação da postura, do tónus (hipotonia ou hipertonia axial e dos membros), da coordenação (descoordenação de movimentos finos), do equilíbrio (ataxia), dos movimentos (involuntários-extrapiramidais), da força muscular (proximal e distal e de relaxamento muscular: não esquecer as doenças neuromusculares que se podem apresentar como um atraso motor e de linguagem, como por exemplo a distrofia muscular de Duchenne - avaliar manobra de Gowers e a distrofia miotónica - avaliar fenómeno miotónico).

Salientar, que são sinais de doença grave do sistema nervoso central a persistência dos reflexos arcaicos do recém-nascido para além do primeiro trimestre de vida, bem como a ausência de reflexos posturais após os sete a oito meses (reflexos de proteção lateral - proteger-se com extensão do braço e abertura da mão em caso de queda lateral, e de páraquedas - proteger-se com extensão dos braços e abertura das mãos em caso de ameaça de queda para a frente).

Nunca esquecer de monitorizar clinicamente a acuidade visual e auditiva (técnicas mais à frente).

Um teste de rastreio tem que ser necessariamente exequível, logo simples e rápido; preciso, válido, quantificável e comparável com a "norma" como na avaliação do crescimento. Na maioria das crianças terá um resultado normal, nas outras apenas fica a suspeita. Deve-se confirmar ou infirmar a/s alteração/ões dentro de um curto espaço de tempo, e só posteriormente referenciar para avaliação de diagnóstico em consultas da especialidade - Pediatria do neurodesenvolvimento. A maior dificuldade na avaliação desta área relativamente à do crescimento relaciona-se com o seu carácter qualitativo, não estando disponível uma unidade de medida quantitativa e objetiva como o cm para o comprimento, ou o kg para o peso. No domínio do DPM e do comportamento, de caráter qualitativo, o observador deve conhecer muito bem o padrão normal, ter uma formação na sua variabilidade e só depois fazer interpretações das possíveis anomalias.

Há múltiplas provas de rastreio, adotaremos nesta lição a recomendada no Programa Nacional de Saúde Infantil e Juvenil (http://www. dgs.pt/?cr=24430) que se baseia nas normas - ou sequências de desenvolvimento de Mary Sheridan (Developmental sequences); que resultaram de um trabalho de mais de 35 anos. 
Seguem-se as idades chave recomendadas para avaliação (não esquecer o oportunismo) e as aquisições que em média se atingem nessa idade nas quatro áreas básicas do DPM: 1 . postura e motricidade global; 2. visão e motricidade fina; 3. audição e linguagem; e 4. comportamento e adaptação social. A presença de sinais de alarme sugere patologia do neurodesenvolvimento.

Apresentam-se as competências do DPM na criança, em idade média, de um modo sumário:

- 1 a 1,5 meses

(avaliar nas consultas dos 1 e 2 meses)

1. Em decúbito ventral - levanta a cabeça. Em decúbito dorsal (posição supina) - a mobilidade dos membros é simétrica; mas pode adotar uma postura assimétrica, com o membro superior do lado para que está virada a face em extensão. Quando tracionada para a posição de sentada tenta controlar a cabeça, o dorso fica arqueado e as mãos fechadas. Em suspensão ventral - a cabeça fica alinhada com o corpo e os membros semi-fletidos.

2. Segue uma bola pendente a $20-25 \mathrm{~cm}$ em 1/4 de círculo (do lado até à linha média).

3. Ao som de uma sineta, roca (guizo) ou voz a $15 \mathrm{~cm}$ do ouvido, pára a atividade e pode voltar os olhos para a fonte sonora.

4. Fixa a face da mãe quando mama. Sorriso social (sorri em resposta a estimulo), presente desde as 4 a 6 semanas de idade. Chora quando se sente desconfortável e responde com sons guturais (laríngeos) em situações de prazer.
Sinais de alarme

1.Ausência de tentativa de controlo da cabeça, na posição sentada. Apresenta hipertonia dos membros inferiores na posição de pé.

2. Nunca segue a face humana.

3.Não reage ao som.

4.Não se mantém em situação de alerta, nem por breves períodos.

\section{- 3 meses}

(avaliar na consulta dos 4 meses)

1. Ao colo mantém a cabeça na posição vertical (segura a cabeça). Em decúbito ventral (bruços) levanta a cabeça e apoia-se nos antebraços. Em decúbito dorsal apresenta postura simétrica, membros com movimentos ritmados, na tração pelas mãos para posição de sentado consegue manter a cabeça ereta e a coluna dorsal direita. De pé, flete os joelhos, não faz apoio.

2. Segue com o olhar, faz pestanejo de defesa e já consegue fazer a convergência ao olhar para um objeto que se aproxima da face. É capaz de seguir uma bola pendente $1 / 2$ círculo e horizontal. Brinca com as mãos abertas, juntando-as na linha média do corpo, segura brevemente um guizo colocado na mão e move-o em direção à face.

3. Reage a sons suaves (voz humana) alterando a atividade, e tenta voltar-se para a fonte sonora.

4. Sorri, quando se Ihe fala. Interessa-se pelo ambiente. Tem boa resposta social à aproximação de uma face. 
Sinais de alarme

1.Não controla a cabeça; membros rígidos em repouso. Assimetrias dos membros. Movimentos pobres.

2.Não fixa nem segue com o olhar a um palmo de distância, mãos quase sempre fechadas. 3.Sobressalta-se com ruídos.

4.Não sorri. Irritabilidade quando se toca.

- 6 meses

1. Segura bem a cabeça e mantem-se sentado com apoio, em decúbito dorsal levanta a cabeça (aumento do tónus axial) e consegue levar o pé à boca (perda do predomínio do tónus em flexão dos membros inferiores). Em decúbito ventral apoia-se nas mãos, com os membros superiores em extensão. De pé, mantém as pernas em extensão, suporta o peso e tenta saltar (perda do predomínio do tónus em flexão dos membros).

2. Apresenta boa convergência ocular (estrabismo anormal). Repara em objetos pequenos (smarties). Consegue apanhar um objeto com ambas as mãos (preensão palmar e cubital); leva-o à boca e transfere de uma mão para a outra. Ainda não procura o objeto que cai.

3. Vocaliza sons mono e dissílabos (galreio). Volta-se para sons ao nível de $45 \mathrm{~cm}$ do ouvido.

4. Muito ativa, atenta e curiosa, dá gargaIhadas; agita-se à vista dos alimentos.

Sinais de alarme

1. Ausência de controlo da cabeça (hipotonia axial). Tem membros inferiores rígidos e faz passagem direta à posição de pé quando se tenta sentar (hipertonia distal-espasticidade). Assimetrias. Abdução limitada das coxas (inferior a 150 graus), ou assimetria.

2. Não se interessa por objetos, nem the pega. Estrabismo.

3. Não galreia, nem reage aos sons.

4. Tem desinteresse pelo ambiente.

- 9 meses

1. Já se senta sózinha e mantem-se sentada por 10 a 15 minutos, apanha objeto colocado atrás. Põe-se de pé com apoio, mas não se consegue baixar. Rasteja.

2. Apanha pequeno objeto entre o indicador e o polegar (pinça digito-polegar). Leva tudo à boca. Atira os objetos ao chão deliberadamente e depois procura-os. Aponta com o indicador para objetos ou foco de interesse distante.

3. Tem atenção rápida para os sons próximos, e distantes. Localiza sons suaves a $90 \mathrm{~cm}$ primeiro abaixo e depois acima do nível do ouvido. Imita sons, ou gestos do adulto.

4. Come pela sua mão bolacha ou pedaço de pão. Mastiga. Distingue os familiares dos estranhos, o que a leva a ter receio de desconhecidos. Faz gracinhas e imitação de comportamentos sociais ("a pitinha põe o ovo", "juizinho", "palminhas", diz adeus com a mão...)

\section{Sinais de alarme}

1. Não se senta. Permanece sentada e imóvel sem procurar mudar de posição. 
2. Apresenta assimetrias. Não tem preensão palmar, não leva objetos à boca.

3. Não reage aos sons. Vocaliza monotonamente ou perde a vocalização.

4. É desinteressada na relação com os familiares. Não imita.

- 12 meses

1. Anda só, ou pela mão. Sentada roda 180 graus e levanta-se sozinha. Gatinha.

2. Explora com energia os objetos, cede-os; atira-os sistematicamente ao chão. Procura um objeto que viu esconder. Tem interesse visual para perto, e longe.

3. Tem resposta rápida aos sons suaves, mas habitua-se depressa. Dá pelo nome e volta-se. Compreende ordens simples verbais (sem a ajuda de gestos) "dá, cá" e "adeus". Tem Jargão [vocalização com entoação (prosódia) de conversa-diálogo, embora sem palavras percetíveis]. Diz uma palavra com significado.

4. Bebe por copo com ajuda. Segura a coIher, mas não a usa. Colabora no vestir levantando os braços. Quer o adulto por perto. Demonstra afeto.

\section{Sinais de alarme}

1. Não se põe, nem se mantem de pé. Não se desloca.

2. Não pega nos brinquedos ou fá-lo só com uma mão (preferência manual).

3. Não responde à voz.

4. Não brinca nem estabelece contacto. Desinteresse pelo ambiente. Não mastiga.
- 18 meses

1. Já anda bem sózinha e sobe escadas com ajuda. Apanha brinquedos do chão.

2. Constroi torre de 3 cubos; faz rabiscos para cá e para lá, mostrando preferência manual; observa um livro, e volta várias páginas de cada vez.

3. Usa 6 a 26 palavras com significado e compreende muitas mais. Mostra em si ou num boneco os olhos, o cabelo, o nariz e os sapatos (identificação de partes do corpo).

4. Bebe por um copo sem entornar muito, levantando-o com ambas as mãos. Segura a colher e leva a comida à boca. "Ajuda" nos trabalhos domésticos. Indica necessidade de ir à casa de banho. Não gosta que lhe peguem. Exige muita atenção. Não coopera na brincadeira com outras crianças. Egocêntrica, faz birras.

\section{Sinais de alarme}

1. Não se põe de pé, não suporta o peso sobre as pernas. Anda sempre na ponta dos pés.

2. Não faz pinça - não pega em nenhum objeto entre o polegar e o indicador. Ainda leva tudo à boca, ou atira tudo ao chão.

3. Não responde quando a chamam. Não vocaliza espontaneamente.

4. Não se interessa pelo que a rodeia; não estabelece contacto, não aponta para mostrar. Deita os objetos fora, ou leva-os sistematicamente à boca, não sabe para que servem. 
- 2 anos

1. Corre. Sobe e desce escadas com os dois pés no mesmo degrau. Dá pontapés.

2. Imita rabisco circular. Gosta de ver livros e folheia uma página de cada vez. Constrói torre de 6 cubos.

3. Diz o primeiro nome. Nomeia objetos. Usa funcionalmente frases de duas a três palavras e pronomes (minha, meu, teu...). Cumpre ordens simples (sem a ajuda de gestos) do tipo: põe a colher na chávena, vai abrir a porta, apaga a luz.

4. Usa bem a colher. Bebe por um copo e coloca-o no lugar sem entornar. Coloca o chapéu e os sapatos. Brinca sozinha, imitando cenas da vida doméstica. Manifesta claramente a sua vontade. Continua egocêntrica, dependente do adulto, comportamento de oposição e desafio, com birras se contrariada.

\section{Sinais de alarme}

1. Não anda sozinha.

2. Deita os objetos fora. Não constrói nada.

3. Não parece compreender o que se the diz. Não pronuncia palavras inteligíveis.

4. Não se interessa pelo que está em seu redor. Não estabelece contacto. Não procura imitar.

- 3 anos

1. Tem equilíbrio momentâneo num pé. Sobe escadas com um pé em cada degrau (alternado). Desce com os dois pés no mesmo degrau.

2. Constrói torre de 9 cubos. Imita ( 3 anos) e copia (3 anos e meio) a ponte de 3 cubos.
Copia o círculo (com modelo prévio) imita a cruz (o adulto faz em simultâneo). Combina (associa) duas cores geralmente o vermelho e o amarelo. Ainda confunde o azul e o verde.

3. Diz o nome completo e o género. Tem vocabulário extenso mas pouco compreensível por estranhos. Tem defeitos de articulação e imaturidade na linguagem. Faz perguntas.

4. Pode despir-se, se lhe desabotoarem o vestuário. Vai sozinha à casa de banho. Come com colher e garfo. Comportamento de oposição e desafio a melhorar. Confunde fantasia com realidade.

- 4 anos

1. Equilibra-se num pé, sem apoio, 3 a 5 segundos. Sobe e desce com um pé em cada degrau. Salta num pé.

2. Constrói escada de 6 cubos. Copia a cruz. Combina (associa) e nomeia quatro cores básicas.

3. Sabe o nome completo, a idade, o sexo e habitualmente a morada. Apresenta linguagem compreensível. Tem apenas algumas substituições infantis.

4. Pode vestir-se e despir-se só com exceção de abotoar atrás, e dar laços. Gosta de brincar com crianças da sua idade. Sabe esperar pela sua vez. Comportamento cooperante. Ainda confunde fantasia e realidade.

- 5 anos

1. Equilibra-se num pé, sem apoio, 3 a 5 segundos, com os braços dobrados sobre 
o tórax. Salta alternadamente num e noutro pé.

2.Constrói escada de 10 cubos. Copia o quadrado e o triângulo. Conta cinco dedos de uma mão e nomeia quatro cores.

3. Sabe o nome completo, a idade, morada e habitualmente a data de nascimento. Tem vocabulário fluente e articulação geralmente correta - pode haver confusão nalguns sons.

4. Veste-se sozinha. Lava as mãos e a cara e limpa-se sozinha. Escolhe os amigos. Compreende as regras do jogo. Comportamento cada vez mais cooperante.

\section{Sinais de alarme}

\section{4 a 5 anos}

Linguagem incompreensível, não mantém conversa, não compreende, não faz perguntas. Problemas do comportamento (birras excessivas; comportamento repetitivo; agitação psicomotora). Tem estrabismo ou suspeita de défice visual.

\section{Para rastreio da perturbação do espectro}

do autismo, propõe-se a aplicação de um breve questionário Modified Checklist for Autism in

Toddlers (M-CHAT) aos 18 e/ou 24 meses que se encontra disponível em (http://mchatscreen. com/wp-content/uploads/2015/05/M-CHAT_ Portuguese2.pdf), assim como a respetiva cotação. É um questionário muito simples composto de 23 perguntas (resposta sim ou não) que devem ser preenchidos pelos pais/cuidadores, não necessitando de qualquer preparação prévia. A validade desta escala tem sido bem estudada no grupo etário entre os 16 e os 30 meses. Apesar da boa sensibilidade (85\%) e especificidade (93\%), apresenta um valor preditivo positivo baixo o que leva a ter alguma atenção nos casos com resultado positivo. Não se deve portanto, prescindir da observação da criança e do esclarecimento das respostas dadas, aliás como é de boa prática médica antes de referenciação. A cotação da escala é muito rápida (dois minutos). São considerados resultados positivos quando há falha em pelo menos três das 23 perguntas, ou em duas das seis consideradas críticas (acessível em: http://www. dgs.pt/?cr=24430, Programa Nacional de Saúde Infantil e Juvenil, páginas 91 e 92).

Face a uma suspeita de atraso ou desvio nas aquisições do desenvolvimento psicomotor há que ter em conta que os limites do normal são muito amplos e que o "comportamento" e a "colaboração" da criança durante uma prova poderão ser afetados por inúmeros fatores.

Por tudo isto, antes de alarmar a família, convém repetir a avaliação num prazo razoável (um a três meses, se for na idade pré-escolar, no lactente o intervalo de verificação tem que ser inferior). Por vezes assiste-se a recuperações notáveis.

A perda (regressão) de aquisições previamente adquiridas, se confirmada e mantida, deve ser sempre interpretada como um sinal de doença do neurodesenvolvimento.

Perante um atraso nas aquisições do DPM, global, ou de uma área em particular, há que tentar interpretar onde reside o problema. De um modo simplista podemos raciocinar de acordo com o esquema da figura 3. 


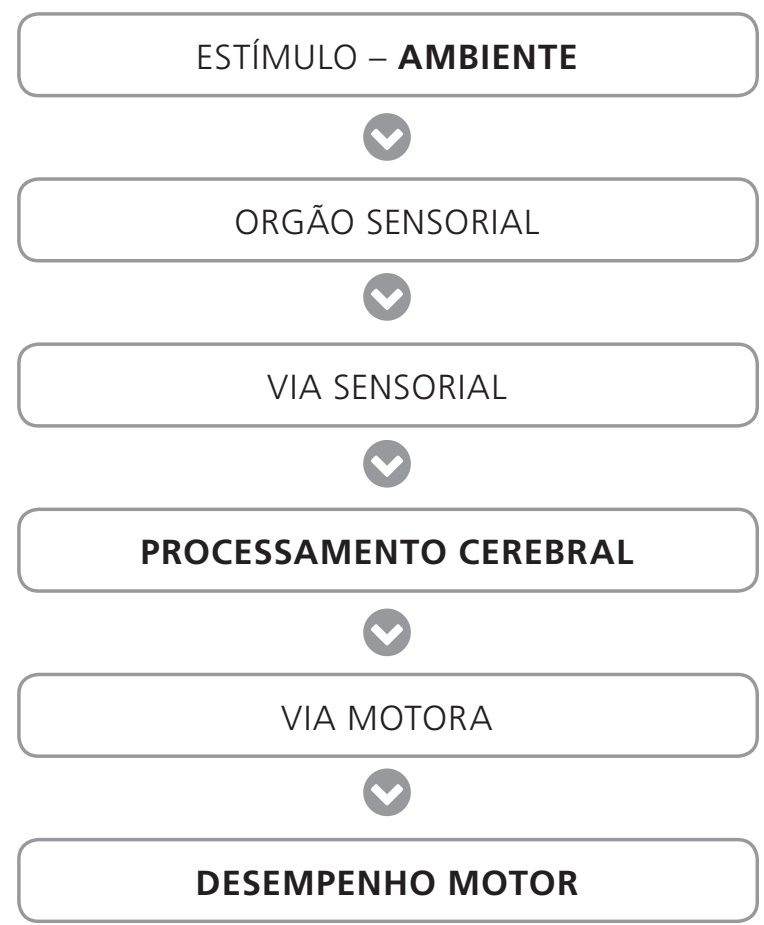

Figura 3 - Esquema das etapas funcionais que poderão estar afetadas perante um atraso ou desvio nas aquisições ou competências do neurodesenvolvimento.

Explicando, para que se aprenda/desempenhe qualquer tarefa terá que haver estímulo sensorial através de modelo do ambiente, fazê-lo chegar ao cérebro (órgão+via sensorial - via aferente), onde será processado a nível cerebral, o que depois determinará através de via eferente um desempenho motor - execução (via motora, aparelho motor). Exemplificando, uma falha na área da linguagem ou da visuomotricidade, pode acontecer porque a criança nunca foi estimulada, não ouve ou não vê, não processa a informação (não compreende - défice intelectual), ou então não executa a tarefa por problemas motores.

Reter que a causa mais frequente dos problemas do DPM e do comportamento têm origem em disfunção cerebral (processamento central). A "falta de estímulo" é um mito entre nós.

Técnica de avaliar o neurodesenvolvimento

O material necessário para avaliar o DPM, é pouco e simples. Existe um Kit padronizado, disponível no mercado referente à aplicação da "Escala de Avaliação das Competências no Desenvolvimento Infantil" dos 0 aos 5 anos. Consta de uma bola pendente (pequena, tipo pompom, com fio), uma sineta e/ ou roca (brinquedo de bebé); 10 cubos (dimensões $2.5 \times 2.5 \mathrm{~cm}$ ), coloridos: amarelo, vermelho, verde e azul; bolinhas pequenas (smarties, passas de uva, bolinhas de enfeitar bolos); boneca; colher, garfo e escova de cabelo de pequenas dimensões (brinquedos); livro com gravuras; copo/caneca com asa; bola pequena com diâmetro de 5 a $6 \mathrm{~cm}$, maleável; painel com 10 cores + cartões de correspondência (azul escuro, laranja, roxo, preto, amarelo, cor-de-rosa, verde, castanho, vermelho e azul-claro). E claro está, papel e lápis para o grafismo.

A observação deve ser levada a cabo numa sala pouco "enfeitada", calma e ampla, onde a criança e a mãe/pai se sintam confortáveis. Só se deve ter o material necessário, se for muito distrai. É melhor falar com os adultos até que a criança relaxe. Aproveitar para interrogar sobre as aquisições e as preocupações (se as houver) acerca do DPM e do comportamento, e fazer a história. O examinador deve colocar-se ao nível da criança: sentada na mesa à sua frente, ou então ambos no chão. Será mais fácil prender-lhe a atenção, ao mesmo tempo que se observa o seu movimento de olhos, de boca e de mãos, nas diferentes tarefas. 
A mãe tem que estar presente, com a criança ao colo ou sentada a seu lado (dependendo da idade). A avaliação deve iniciar-se pela área da visuomotricidade: brincando com cubos, livros; o material deve ser novidade para a criança. A avaliação da linguagem surgirá no diálogo espontâneo. O discurso do observador tem que ser adequado à compreensão da criança: para um rapazinho de 18 meses, perguntar onde está o nariz do João em vez de o "teu" nariz. O sucesso da resposta deve ser elogiado; em caso de falha a nossa exclamação deverá ser neutra, nunca pejorativa.

Para que uma criança "colabore" na avaliação, de modo a que possamos obter um resultado correto no menor tempo possível, teremos de conhecer o seu comportamento e controle da atenção, nas diferentes fases do desenvolvimento. Só depois vem o exame físico.

\section{Factos a reter}

Mais importante que o produto da avaliação do DPM decorrente de uma consulta isolada, será o percurso evolutivo do resultado de observações seriadas que permitam traçar o "perfil de neurodesenvolvimento da criança", tal como no crescimento. A sua interpretação face à norma, deverá ter sempre em conta a história clínica da criança e o meio em que vive.

Não ficaria completa esta lição se duas funções sensoriais básicas para as aquisições do DPM não fossem abordadas como a audição e a visão.
Audição e Visão

\section{Audição}

A função auditiva é primordial para a aquisição da linguagem verbal, aprendizagem escolar e adaptação social. Na verdade, a identificação precoce de défices sensoriais permanece um dos principais objetivos do rastreio das aquisições do DPM. Só uma intervenção terapêutica e educacional atempada, melhora o futuro das crianças com surdez. O rastreio universal mas maternidades portuguesas através das otoemissões acústicas é hoje uma realidade. Contudo, a atenção clínica à acuidade auditiva deve ser uma prioridade em todas as consultas de saúde infantil. A surdez neurosensorial profunda bilateral atinge uma em cada mil crianças, mas os défices mais moderados são seis vezes mais frequentes e passam facilmente despercebidos, a todos.

Como monitorizar em contexto clínico de rotina a acuidade auditiva? Como reage a criança ao estímulo sonoro nas diferentes fases do neurodesenvolvimento e comportamento?

- Recém-nascido

A uma fonte sonora, súbita, intensa e próxima (bater palmas, bater à porta), responde com um reflexo de Moro espontâneo, uma paragem na mamada, um susto.

- 1 mês

Dá conta de sons prolongados, como o do aspirador. Reagindo, quando começa e quando acaba.

- 4 meses

Tenta localizar vozes conhecidas, voltando os olhos e a cabeça. 


\section{- 7 a 20 meses}

Criança sentada ao colo da mãe. São necessárias duas pessoas. Um observador em frente da criança (a uma distância de dois metros), prendendo a sua atenção com um brinquedo (técnica de distração). Simultaneamente outra pessoa atrás, fora do seu alcance visual, estimula com uma fonte sonora (sineta, roca, colher raspando numa chávena, voz humana "Ss-ss-som agudo, Ôô-ôô-som grave). A resposta desejada é que volte a cabeça, localizando visualmente a fonte sonora. Se a resposta for duvidosa, deve-se reavaliar quatro semanas depois. Se for ausente enviar à consulta de otorrinolaringologia. Não perder a oportunidade de validar clinicamente a acuidade auditiva até aos 12 meses.

Depois do ano de idade pode ser difícil interpretar a resposta dado que a criança nesta fase, pelas suas características comportamentais, pode não ter interesse em confirmar a fonte sonora apesar de a ouvir...só tentando algo que a motive.

Após esta idade a audição pode ser avaliada por ordens verbais. Colocar vários objetos em cima de uma mesa (colher, chávena, cubos, livros...), fazendo então o pedido em voz baixa a cerca de $45 \mathrm{~cm}$ do ouvido de ambos os lados, sem que a criança observe a face/boca (teste de discriminação verbal).

Na idade escolar, usar a prova logométrica. A criança voltada de costas deve repetir as palavras do quadro 1 proferidas em voz baixa pelo observador à distância de três metros. Se tiver erros frequentes deve ser referenciada à consulta de otorrinolaringologia.

\begin{tabular}{|l|l|l|}
\hline $\begin{array}{l}\text { OUVIDOS } \\
\text { LIVRES }\end{array}$ & $\begin{array}{l}\text { OUVIDO } \\
\text { DIREITO }\end{array}$ & $\begin{array}{l}\text { OUVIDO } \\
\text { ESQUERDO }\end{array}$ \\
\hline NÃO & RÃ & CHÁ \\
\hline SOL & SAL & MAU \\
\hline PAU & CÉU & MÓ \\
\hline CHÁ & VACA & LÃ \\
\hline FACA & CABRA & PEIXE \\
\hline VELHA & GATO & DISCO \\
\hline GUITA & XAILE & GAITA \\
\hline TOSSE & TRAVÃO & VINHO \\
\hline FEIRA & FOLHA & FAVA \\
\hline MARÉ & VELHA & CHAVE \\
\hline PAI & MILHO & NINHO \\
\hline REI & MAPA & PIPA \\
\hline
\end{tabular}

Quadro 1. Prova logométrica para crianças de idade escolar.

Atenção - na avaliação da acuidade auditiva, evitar pistas visuais. No primeiro, e até no segundo ano de vida o perfil de desenvolvimento de uma criança com surdez profunda pode passar por normal. Parece que compreendem tudo - obedecem a pedidos, isso acontece porque é habitual apontarmos (gesticularmos - darmos pistas visuais) em simultâneo.

\section{Visão}

A ambliopia atinge 2 a $5 \%$ das crianças. Se precocemente corrigida, verifica-se uma compensação funcional mais ou menos completa; para tal é indispensável rastrear essas anomalias precocemente.

A vigilância da visão nas consultas de saúde infantil tem como objetivo principal a prevenção do défice visual permanente, se problemas como o estrabismo, erros de refração e outros mais raros como as cataratas não forem 
diagnosticados e tratados em tempo útil, de preferência na idade pré-escolar. O rastreio deve incidir em todas as idades, iniciando-se precocemente, logo no recém-nascido em que se deve garantir a ausência de opacidades dos meios transparentes do olho, através da pesquisa do reflexo vermelho.

A resposta da criança ao estímulo visual, tal como na audição, vai depender do grau de neuromaturação atingido. O recém-nascido só vê 6/200 (vê a seis metros o que uma acuidade visual normal do adulto vê a 200). Aos três meses, 95\% dos lactentes fazem convergência do olhar o que the permite focar objetos que se aproximam, como observar e brincar com as mãos na linha mediana do corpo, próximo da face. Entre os seis e os oito meses a visão periférica já lhe permite ir à procura dos objetos. Entre os 18 e os 36 meses atinge a acuidade visual do adulto.

Como monitorizar a visão em contexto clínico de consulta de rotina de saúde infantil?

\section{- Recém-nascido}

Fixa e segue a face da mãe a $25 \mathrm{~cm}$ (a distância da posição de quando está ao colo ou a mamar) numa linha horizontal. Volta-se para a luz difusa e pestaneja com um foco luminoso intenso.

\section{- 1 a 3 meses}

Avaliar em posição supina. Fixa e segue uma face à distância de cerca de $30 \mathrm{~cm}$. Converge o olhar à aproximação da face do examinador, brinca e olha para as mãos na linha mediana. Pelas seis semanas ambos os olhos se conjugam para seguir um estímulo luminoso. Pelos três meses perde-se o estrabismo fisiológico.
- 9 meses a 2.5 anos

Aos nove meses é capaz de fixar e seguir com o olhar uma bolinha prateada dos bolos, rolando em fundo escuro, a três metros de distância. Depois dos 12 meses segue-a a seis metros. Avaliar os olhos em separado (tapando suavemente com a mão um deles) na suspeita de ambliopia (teste da preferência ocular), mostram desconforto com o olho que vê menos.

\section{- 3 a 5 anos}

Dos três anos em diante, poderemos usar uma prova de letras exigindo apenas que a criança combine (associe) as letras com formas mais simples (próximas do grafismo que já é capaz de fazer) - O H X T V U (teste de Sonksen Silver Acuity system).

\section{A reter, nunca esquecer de pesquisar} o estrabismo; depois dos seis meses é sempre anormal. O reflexo de uma luz fixa deve projetar-se simetricamente nas duas córneas, se não houver estrabismo. O nistagmo pode ser um sinal de défice visual.

É indispensável avaliar os olhos separadamente; de outro modo pode ignorar-se uma ambliopia de um deles.

O bebé pequeno que não responde ao estímulo visual, pode justificar-se por diferentes causas de entre elas os défices na acuidade visual, na interação social ou na capacidade intelectual.

\section{Patologias do neurodesenvolvimento}

As patologias do neurodesenvolvimento são um grupo heterogéneo de entidades médicas que têm por base anomalias cerebrais ou 
sensoriais de carácter permanente. A maioria é de origem genética e manifesta-se desde os primeiros anos de vida por atraso ou desvio nas aquisições do DPM e por alterações do comportamento. Estamos a considerar neste âmbito condições clínicas com critérios de diagnóstico bem estabelecidos pela comunidade médica internacional. Podemos apresentar estas patologias em dois subgrupos. O de maior gravidade, onde se enquadra a perturbação do desenvolvimento intelectual (quociente intelectual global inferior a 70), a paralisia cerebral, a perturbação do espetro do autismo, a surdez neurosensorial profunda e a cegueira. O outro agrega as perturbações que apesar do seu menor impacto clínico, têm uma repercussão relevante nas aprendizagens adaptativas e no sucesso académico, bem como na qualidade de vida familiar, tais como: os problemas comportamentais de défice de atenção e hiperatividade, de desafio, de oposição e de conduta, as perturbações da memória, da perceção, da coordenação motora, da linguagem, da flexibilidade cognitiva, da interacção social e as perturbações específicas de aprendizagem escolar de entre outras, que no seu conjunto, são muito frequentes.

No global, estas doenças afetam cerca de um quinto da população de idade pediátrica, sendo das patologias crónicas mais frequentes, com tendência a aumentar, e das que representam maior sobrecarga socioeconómica. A maioria dos quadros mantem-se na vida adulta, devendo ser posteriormente referenciados para consultas de Psiquiatria com formação em patologia do neurodesenvolvimento.
Quando se diagnostica uma patologia do neurodesenvolvimento os pais colocam de imediato várias questões: porque é que aconteceu? Pode voltar a acontecer em futuros filhos? Qual o futuro da criança? O que é que se pode fazer?

A resposta a estas questões dependerá não só do nível funcional da criança e dos problemas que se associam, como também de um diagnóstico específico e causal; só então poderemos oferecer um aconselhamento genético e uma perspetiva de perfil evolutivo. Mesmo nos melhores centros a maioria dos casos das perturbações do neurodesenvolvimento permanece sem identificação da etiologia. Nos casos em que é conhecida predominam as causas pré-natais (alterações genéticas, metabólicas, endócrinas, teratogenecidade, infeções, muito baixo peso, prematuridade e gemelaridade), seguem-se as perinatais (asfixia, infeções) e mais raramente incidentes pós-natais (infeções cerebrais, acidentes).

A investigação etiológica deve ser discutida caso a caso e orientada numa consulta de Pediatria do neurodesenvolvimento em colaboração com outras especialidades e disciplinas como a genética médica, as doenças hereditárias do metabolismo, a neuropediatria, a biologia molecular e a imagiologia, de entre outras.

As anomalias cromossómicas e monogénicas são as causas mais vezes identificadas como seja a trissomia 21, os síndromes de X frágil, de Williams, de Angelman, de Rett, de Prader-Willi, entre outros. O hipotiroidismo congénito, uma causa frequente de défice intelectual no passado, é de há uns anos para cá rapidamente compensado com a administração diária de hormonas 
tiroideias, graças ao rastreio neonatal. O mesmo se passa com a fenilcetonúria e outras doenças hereditárias do metabolismo que são desde os primeiros dias de vida tratadas com dietas adequadas, evitando a lesão neurológica.

Porém, poucas são ainda as causas tratáveis. Também não dispomos de fármacos curativos. No entanto, muito pode ser feito por estas crianças e famílias. O diagnóstico funcional deve ser precoce. A família precisa de ajuda de uma equipa especializada multidisciplinar de que fazem parte médicos, terapeutas (terapeutas da fala, terapeuta ocupacional, fisioterapeuta), profissionais da psicologia e da educação e técnicos de serviço social, de entre outros. A intervenção deve ser específica e holística, sempre que possível no ambiente natural da criança, recorrendo aos recursos da comunidade (Sistema Nacional de Intervenção Precoce na Infância - ver lição específica, e à Lei da Educação Especial do ensino regular, DecretoLei $n^{\circ} 3 / 2008$ ).

Uma boa e forte relação "médico-doente-família" ou "equipa-doente-família", no sentido mais clássico e nobre do termo, tem nestas perturbações, a repercussão máxima na melhoria da qualidade de vida destas famílias.

\subsection{FACTOS A RETER}

As crianças com perturbação do neurodesenvolvimento, independentemente da sua causa, devem ser avaliadas de modo a traçar um perfil de DPM e comportamento que dê a conhecer as suas áreas fracas (resultantes de deficiências específicas) e eventualmente as suas potencialidades - áreas fortes.

O objetivo de intervenção será o de compensar a deficiência melhorando as áreas fracas, e oferecer a oportunidade de deixar revelar as suas potencialidades, de modo que a criança venha a atingir a mais completa e feliz integração social.

\section{Leitura complementar}

Oliveira, G; Duque, F; Duarte, C; Melo, F; Teles, L; Brito, M; Vale, M. C; Guimarães, M. J; Gouveia, R. «Pediatria do Neurodesenvolvimento. Levantamento nacional de recursos e Necessidades». Acta Pediátrica Portuguesa 2012, 43(1): $1-7$

Oliveira, G.. «Autismo: diagnóstico e orientação. Parte I Vigilância, rastreio e orientação nos cuidados primários de saúde», Acta Pediátrica Portuguesa 2009, 40(6): 278 - 87 Normal child development, hearing and vision. In:Lissauer T, Clayden G. Illustrated Textbook of Paediatrics. 4th ed. Elsevier Health Sciences. 2011. p 31- 47.

Programa nacional de saúde infantil e juvenil. Lisboa: Direçãogeral da saúde; 2013

Oliveira G. Visão na criança - normas práticas de avaliação, perspectiva pediátrica-1ª. Saúde Infantil 1994, 16: 47 -51.

Oliveira G. Visão na criança - normas práticas de avaliação, perspectiva pediátrica- $2^{a}$ parte. Saúde Infantil 1994, 16: $97-101$. 